\title{
Gritty Students Succeed in the Teacher Recruitment Examination: A Longitudinal Survey in a Japanese Teacher Training University
}

\author{
Ryosuke Sakurai *, Takumi Watanabe *
}

\begin{abstract}
Grit, which concerns perseverance and passion to achieve long-term goals, predicts success in a wide range of areas. As a preliminary step toward the application of grit in institutional research (IR), this study longitudinally analyzes the impact of individual differences regarding level of grit on results in teacher recruitment examinations. In this study, undergraduate students at a Japanese teacher-training university $(N=629)$ responded to a questionnaire survey. The results showed that students with higher grit were more likely to take the teacher recruitment exam, and also to pass the second part of this exam. This effect persisted even after controlling for self-control, a noncognitive skill that is strongly associated with goal achievement. It was also found that perseverance of effort and consistency of interest, which are subfactors of grit, had differing effects on the results of teacher recruitment exams, respectively: while consistency of interest had an effect on the probability of taking the teacher recruitment exam, perseverance of effort had an effect on the probability of passing the second part of the exam. We concluded that consideration of grit can help teacher-training universities resolve the issue of producing high numbers of high-quality teachers.
\end{abstract}

Keywords: grit, institutional research, noncognitive skill, teacher recruitment examination

\section{Introduction}

In Japan, the competition ratio for public-school-teacher recruitment examinations has shown a continuous decline over the past two decades [2]. More specifically, the competition ratio has dropped from a peak of 13.3 in 2000 to 4.2 in 2019. In particular, some prefectures (e.g., Hokkaido) are experiencing an extremely serious issue in terms of teacher quality assurance, with the competition ratio for the most recent teacher recruitment examinations falling below two [3]. Under these circumstances, there is currently a strong demand for teacher-training universities to produce as many high-quality teachers as possible. For example, Hokkaido University of Education, a Japanese teacher-training university, has set a social role to raise the percentage of

\footnotetext{
* Hokkaido University of Education, Hokkaido, Japan

This paper is an extended version of a paper presented at the 9th International Conference on Data Science and Institutional Research (DSIR 2020) [1].
} 
graduates employed as teachers to $75 \%$ in consultation with the Ministry of Education, Culture, Sports, Science and Technology [4]. Institutional research (IR) in teacher-training universities is required to provide university executives with the basic evidence needed to help them implement educational reforms to accomplish this kind of task. This raises the question: how should teacher-training-university-focused IR approach this issue?

One method of examining this is the adoption of a psychological approach. Specifically, this includes identifying the individual characteristics that determine a student's probabilities of taking and passing teacher recruitment examinations, and recommending reforms to improve these characteristics. In recent years, a concept called "grit" has gained attention as a personal characteristic that determines the achievement of such long-term goals [5].

\subsection{Definition and Measurement of Grit}

Grit is defined as perseverance and passion to achieve long-term goals [5]. Grit is a type of noncognitive skill as distinguished from the ability measured by Intelligence Quotient (IQ) tests and academic achievement tests (i.e., cognitive ability). Currently, grit is primarily measured using the Grit Scale, a 12-item self-report scale that comprises two factors: "perseverance of effort" and "consistency of interest." Perseverance of effort reflects a tendency to continually strive to achieve a goal even when encountering difficulties (this is typified by the attitude: "I finish whatever I begin"), while consistency of interest reflects the tendency to remain interested in a single goal for a long time (e.g., "I often set a goal but later choose to pursue a different one" [a reverse-scored item]).

Although both of these factors are said to reflect different aspects of grit, as a result of their high predictive power most studies combine the scores for these factors to form a single grit score [5]. Despite this, however, a meta-analysis of grit has emphasized that each factor should be analyzed separately [6]. Furthermore, this meta-analysis showed that perseverance of effort is a better predictor of performance and success than either consistency of interest or overall grit.

A short version of the Grit Scale (Grit-S) also exists [7], which removes two items from the perseverance of effort and consistency of interest subscales, respectively. While the Grit-S has the advantage of reducing the burden on respondents by containing fewer items, there is also the criticism that the deletion of items removes a core element of the definition of grit (persistence in effort and passion despite experiencing difficulties and obstacles) [8].

\subsection{Grit as a Determinant of Success}

The process of achieving long-term goals usually involves a number of failures, which can frustrate people, and achieving such goals requires the investment of considerable time in effortful practice in order to become proficient at the tasks in question. People with high levels of grit do not lose their interest and passion when they encounter such difficulties and obstacles, but persistently strive to achieve their goals. As a result, high grit is associated with successfully achieving goals [9].

Studies have repeatedly shown that people with higher levels of grit perform better than individuals with lower levels of grit in a variety of domains. For example, one of the most representative studies on grit was a large-scale survey of cadets at the US Military Academy at West Point [10]. This longitudinal analysis of more than 10,000 cadets to determine whether their grit and their cognitive and physical abilities at the time of entry predicted whether they would be able both to complete the grueling six weeks of basic training immediately after entry and to 
graduate in four years. The study consistently found that cadets with higher grit were more likely to complete the grueling military training. On the other hand, it also showed that cognitive and physical abilities do not predict dropout from this training. It was also shown that grit and physical ability significantly predicted graduation from West Point in four years, whereas cognitive ability did not. The above results may robustly indicate that people with higher grit are more likely to succeed in achieving long-term and challenging goals.

One study of grit that is particularly important in terms of teacher training is a survey of novice teachers in elementary, middle, and high schools [11]. This study also confirmed that teachers with higher levels of grit are more proficient at teaching and are less likely to leave their jobs. This result indicates that instilling high levels of grit in student could lead to an improvement in the future quality of teachers. The study also confirmed that variables such as college grade point average (GPA) and Scholastic Assessment Test (SAT) scores are not associated with educational ability or turnover.

Research examining the mechanisms by which grit leads to success reported that the effect of grit on performance is mediated by time spent in "deliberate practice" [12]. Deliberate practice refers to demanding but effective practice that can improve performance. The study found that, among the finalists of a vocabulary contest called the "Spelling Bee," those with higher grit had performed more deliberate practice and, as a result, performed better in the contest.

A particularly important aspect of the above study findings is that the effect of grit persists after controlling for the influence of other variables involved in goal achievement. In fact, grit occasionally shows a higher predictive power than these variables [9]. Thus, individual differences in grit may play a distinct role in the achievement of long-term and challenging goals.

\subsection{Self-Control and Grit}

One noncognitive ability that is particularly relevant to grit is "self-control" [13]. Self-control is defined as the ability to suppress undesirable behavioral tendencies in order to achieve goals. The Self-Control Scale is the most commonly used self-report measure of self-control [14]. In particular, a short version (Brief Self-Control Scale) with 13 items (e.g., "I am good at resisting temptation") extracted from the 36 items of this scale is widely used. Studies have repeatedly shown that high self-control is associated with positive social consequences [15]. Specifically, higher self-control has been found to be associated with better academic performance [16], interpersonal relationships [17], and life satisfaction [18].

Grit and self-control are both noncognitive abilities that predict goal achievement, and are conceptually related; in fact, it has been confirmed that the two are strongly correlated [5]. However, these two concepts are "related but separable" [19]. Specifically, grit represents the ability to maintain over several years a passion to achieve a single goal and to continuously perform associated efforts, while self-control concerns the ability to restrain immediate impulses and temptations that impede the achievement of one or more goals. This means that people with high grit do not necessarily suppress their desires in areas other than those concerning their most important personal goal. On the other hand, people with high self-control do not necessarily continue to strive for long periods of time to achieve a single goal. In other words, grit and self-control differ in terms of the number of goals pursued simultaneously (one vs. more than one, respectively) and in the duration of the pursuit (long-term vs. short-term, respectively). Consistent with this definition, previous studies have shown that grit, when compared to self-control, better predicts the achievement of goals that require long-term commitment (e.g., completion of military training) [5]. 


\subsection{The Present Investigation}

In the context of students in teacher-training universities, grit may have an effect on their achievement of their goal of "becoming a teacher." This is because, in order to pass the teacher recruitment examination, students must maintain consistently high levels of effort for a long period; from the time they enter the university until they complete their fourth year of study. During this period, they must engage in daily lectures, teaching practice, and preparation for examinations. Students who, despite experiencing failures and setbacks during their university life, do not become discouraged and instead maintain their passion for teaching will successfully achieve their goals. Therefore, it is predicted that students with higher grit are more likely to take and pass the teacher recruitment exam.

It is important to verify this prediction from the perspective of IR. This is because clarifying the link between grit and teacher recruitment exam results could provide basic evidence for implementing educational reforms (such as intervention strategies designed to increase grit). However, there has been no previous Japan-based longitudinal study of the association between grit and the probability of taking and passing the teacher recruitment examination, although a cross-sectional study has tested this hypothesis [20]. For IR to make evidence-based recommendations in this regard, it will be necessary to obtain longitudinal findings that afford rigorous estimation of causality.

In this study, we examined the impact of grit on the outcomes of the teacher recruitment examinations. This was performed through a longitudinal survey of students at a Japanese teacher-training university. Furthermore, this study also examined the effects of perseverance of effort and consistency of interest (two subfactors of grit; identified based on suggestions in a previous meta-analysis [6]) on better utilization of grit. In addition, the effects of the full and short versions of the Grit Scale [5], [7] were compared. If there is no great difference in the predictive power of the full and short versions of the Grit Scale, then using the short version will reduce the burden on the student respondents.

\section{Methods}

\subsection{Participants and Procedures}

In approximately April 2017, a questionnaire survey was administered to 629 fourth-year students $(42 \%$ male, $58 \%$ female; $M$ age $=22.15, S D=0.49)$ at a teacher-training university in Japan. This questionnaire measured grit and self-control. In addition to these survey items, we analyzed cumulative GPA and the respondents' results for the teacher recruitment examination (i.e., whether the respondents took the exam, and their results for the first and second parts of the exam).

Prior to the investigation, the research underwent an ethics review by the university's research ethics committee, and approval was obtained to conduct the research. At the beginning of the questionnaire, respondents were informed that no personal information would be collected and that answering the questionnaire was voluntary.

\subsection{Measures}

The Japanese version of the original Grit Scale was used to measure grit [20]. This scale contains a total of 12 question items; six items concerning perseverance of effort and consistency of interest, respectively. Further, based on previous research [7], [10], eight of these items were used 
to also administer the Grit-S. For both of these scales, each item is measured using a five-point Likert scale ranging from 1 ("does not apply at all") to 5 ("applies completely").

The Japanese version of the Brief Self-Control Scale [21] was used to measure self-control. This comprises a total of 13 questions, which are measured using a five-point Likert scale ranging from 1 ("does not apply") to 5 ("applies completely").

\subsection{Teacher Recruitment Examinations in Japan}

The teacher recruitment examination in Japan comprises two parts. The first part consists mainly of a mark-sheet test regarding general education and specialized knowledge, while the second part consists of a written test and an interview. The first part is held in approximately June and the second part is held in approximately August.

\section{Results}

All analyses were conducted using SPSS version 26. Initially, we tested the internal consistency of the Grit Scale $(\alpha=.72)$, the perseverance of effort $(\alpha=.84)$ and consistency of interest $(\alpha$ $=.76)$ subscales, the Grit-S $(\alpha=.69)$, and the Brief Self-Control Scale $(\alpha=.82)$. The results were all sufficiently high, and the means of each scale were used as indicators for each. The descriptive statistics for each variable and the correlations between each variable are presented in Table 1. Grit and self-control were positively correlated $(r=.59)$, similar to previous studies [5].

We then used binary logistic regression models to test whether grit predicts outcomes in the teacher recruitment exam. The results of each binary logistic regression analysis are presented in Table 2.

\subsection{Determinants for Probability of Taking the Teacher Recruitment Examina- tion}

In Model 1A, scores for the Grit Scale showed a significant positive effect on whether students took the teacher recruitment exam (did not take $=0$, took $=1 ; B=0.74, S E=0.26, p=.004$, odds ratio $[\mathrm{OR}]=2.11,95 \%$ confidence interval $[\mathrm{CI}]: 1.26-3.52$ ). In summary, students with higher levels of grit were found to be more likely to take the teacher recruitment exam. Therefore, the results supported the hypothesis. Furthermore, there was a significant positive effect of GPA ( $B$ $=0.51, S E=0.22, p=.026, \mathrm{OR}=1.66,95 \% \mathrm{CI}: 1.06-2.61)$ and a significant negative effect of gender $($ male $=0$, female $=1 ; B=-0.87, S E=0.21, p<.001$, OR $=0.41,95 \%$ CI: $0.27-0.63)$. On the other hand, self-control $(B=-0.36, S E=0.20, p=.080, \mathrm{OR}=0.69,95 \%$ CI: $0.46-1.04)$ and age $(B=-0.17, S E=0.20, p=.373, \mathrm{OR}=0.83,95 \% \mathrm{CI}: 0.56-1.23)$ did not show any significant effect on the probability of taking the teacher recruitment examination.

In Model 1B, in which subfactors of the Grit Scale were entered, consistency of interest showed a significant positive effect $(B=0.49, S E=0.18, p=.008$, OR $=1.63,95 \%$ CI: $1.13-$ 2.34). In other words, students with higher consistency of interest were more likely to take the teacher recruitment exam. On the other hand, perseverance of effort did not show a significant effect $(B=0.30, S E=0.15, p=.050, \mathrm{OR}=1.35,95 \%$ CI: 1.00-1.82). In Model 1C, in which the Grit-S was entered, Grit-S and the Grit Scale showed a significant positive effect $(B=0.54, S E=$ $0.23, p=.022, \mathrm{OR}=1.72,95 \% \mathrm{CI}: 1.08-2.75)$. 
Table 1. Descriptive statistics and correlations.

\begin{tabular}{|c|c|c|c|c|c|c|c|c|c|c|c|}
\hline & 1 & 2 & 3 & 4 & 5 & 6 & 7 & 8 & 9 & 10 & 11 \\
\hline \multicolumn{12}{|l|}{ Determinants } \\
\hline \multicolumn{12}{|l|}{ 1. Grit Scale } \\
\hline 2. Perseverance of Effort & $.74^{* * *}$ & & & & & & & & & & \\
\hline 3. Consistency of Interest & $.64^{* * *}$ & -.04 & & & & & & & & & \\
\hline 4. Grit-S & $.93^{* * *}$ & $.75^{* * *}$ & $.54^{* * *}$ & & & & & & & & \\
\hline 5. Self-Control & $.59^{* * *}$ & $.39^{* * *}$ & $.44^{* * *}$ & $.60^{* * *}$ & & & & & & & \\
\hline \multicolumn{12}{|l|}{$\begin{array}{l}\text { Results of the Teacher } \\
\text { Recruitment Examination }\end{array}$} \\
\hline $\begin{array}{l}\text { 6. Took the Exam or Not } \\
(\text { did not take }=0, \text { took }=1)\end{array}$ & $.10^{*}$ & .07 & $.10^{*}$ & .08 & .02 & & & & & & \\
\hline $\begin{array}{l}\text { 7. Results for the First } \\
\text { Part of the Exam } \\
(\text { failed }=0 \text {, passed }=1 \text { ) }\end{array}$ & .00 & .02 & -.07 & .03 & .09 & - & & & & & \\
\hline $\begin{array}{l}\text { 8. Results for the Second } \\
\text { Part of the Exam } \\
\text { (failed = 0, passed =1) }\end{array}$ & $.20^{* *}$ & $.18^{*}$ & .10 & $.18^{* *}$ & .02 & - & - & & & & \\
\hline \multicolumn{12}{|l|}{ Covariates } \\
\hline 9. GPA & $.18^{* * *}$ & $.17^{* * *}$ & .08 & $.22^{* * *}$ & $.22^{* * *}$ & .02 & $.20^{* *}$ & $.21^{* *}$ & & & \\
\hline $\begin{array}{l}\text { 10. Gender } \\
(\text { male }=0 \text {, female }=1)\end{array}$ & .06 & .04 & .01 & .07 & -.01 & $-.15^{* *}$ & $.13^{*}$ & $.19^{* *}$ & $.38^{* * *}$ & & \\
\hline 11. Age & -.04 & -.05 & -.01 & -.08 & $-.09^{*}$ & -.03 & -.07 & -.09 & $-.14^{* *}$ & $-.10^{*}$ & \\
\hline$M$ & 3.11 & 3.05 & 3.16 & 3.13 & 2.96 & $58 \%$ & $81 \%$ & $60 \%$ & 2.81 & $58 \%$ & 22.15 \\
\hline$S D$ & 0.45 & 0.69 & 0.60 & 0.49 & 0.59 & - & - & - & 0.49 & - & 0.49 \\
\hline$N$ & 624 & 624 & 624 & 624 & 623 & 491 & 287 & 233 & 579 & 513 & 511 \\
\hline
\end{tabular}

Note. The values in the rows and columns for binary variables represent Spearman's rank correlation coefficient; otherwise, Pearson's correlation coefficient.

${ }^{*} p<.05,{ }^{* *} p<.01,{ }^{* * *} p<.001$

GPA: grade point average; Grit-S: Short version of the Grit Scale.

Table 2. Binary logistic regression models predicting the results of the teacher-recruitment examination.

\begin{tabular}{|c|c|c|c|c|c|c|c|c|c|}
\hline & \multicolumn{3}{|c|}{$\begin{array}{l}\text { Took the Exam or Not } \\
(\text { did not take }=0, \text { took }=1)\end{array}$} & \multicolumn{3}{|c|}{$\begin{array}{l}\text { Results for the First Part of } \\
\text { the Exam (failed = 0, passed = 1) }\end{array}$} & \multicolumn{3}{|c|}{$\begin{array}{l}\text { Results of the Second Part of } \\
\text { the Exam }(\text { failed }=0, \text { passed }=1 \text { ) }\end{array}$} \\
\hline & $\begin{array}{c}\text { Model } \\
\text { 1A }\end{array}$ & $\begin{array}{c}\text { Model } \\
\text { 1B } \\
\end{array}$ & $\begin{array}{c}\text { Model } \\
\text { 1C }\end{array}$ & $\begin{array}{c}\text { Model } \\
\text { 2A } \\
\end{array}$ & $\begin{array}{c}\text { Model } \\
\text { 2B } \\
\end{array}$ & $\begin{array}{c}\text { Model } \\
\text { 2C } \\
\end{array}$ & $\begin{array}{c}\text { Model } \\
\text { 3A }\end{array}$ & $\begin{array}{c}\text { Model } \\
\text { 3B } \\
\end{array}$ & $\begin{array}{c}\text { Model } \\
\text { 3C }\end{array}$ \\
\hline Grit Scale & $2.11^{* *}$ & & & 0.56 & & & $3.00^{* *}$ & & \\
\hline Perseverance of Effort & & 1.35 & & & 0.88 & & & $1.82^{*}$ & \\
\hline Consistency of Interest & & $1.63^{* *}$ & & & 0.55 & & & 1.62 & \\
\hline Grit-S & & & $1.72^{*}$ & & & 0.72 & & & $2.41^{*}$ \\
\hline Self-Control & 0.69 & 0.68 & 0.75 & 1.53 & 1.60 & 1.39 & 0.66 & 0.67 & 0.72 \\
\hline GPA & $1.66^{*}$ & $1.67^{*}$ & $1.63^{*}$ & $2.34^{*}$ & $2.33^{*}$ & $2.40^{*}$ & 1.85 & 1.84 & 1.72 \\
\hline $\begin{array}{l}\text { Gender } \\
(\text { male }=0, \text { female }=1)\end{array}$ & $0.41^{* * *}$ & $0.41^{* * *}$ & $0.42^{* * *}$ & 1.55 & 1.58 & 1.52 & $1.86^{*}$ & $1.87^{*}$ & $1.91^{*}$ \\
\hline Age & 0.83 & 0.83 & 0.85 & 0.76 & 0.79 & 0.74 & $0.49^{*}$ & $0.50^{*}$ & $0.50^{*}$ \\
\hline Nagelkerke $R^{2}$ & .07 & .07 & .06 & .08 & .08 & .07 & .14 & .14 & .12 \\
\hline$N$ & & 484 & & & 284 & & & 230 & \\
\hline
\end{tabular}

Note. The values in the rows for explanatory variables represent odds ratios.

${ }^{*} p<.05,{ }^{* *} p<.01,{ }^{* * *} p<.001$

GPA: grade point average; Grit-S: Short version of the Grit Scale. 


\subsection{Determinants of Probability of Passing the First Part of the Teacher Re- cruitment Examination}

In Model 2A, scores for the Grit Scale did not show a significant effect on whether students passed the first part of the teacher recruitment exam (failed $=0$, passed $=1 ; B=-0.58, S E=0.41$, $p=.164, \mathrm{OR}=0.56,95 \%$ CI: $0.24-1.26$ ). This result does not support the hypothesis. Meanwhile, GPA showed a significant positive effect $(B=0.85, S E=0.39, p=.030, \mathrm{OR}=2.34,95 \%$ CI: $1.08-5.04)$. On the other hand, self-control $(B=0.42, S E=0.33, p=.202, \mathrm{OR}=1.53,95 \%$ CI: 0.79-2.96), gender ( $B=0.44, S E=0.33, p=.192, \mathrm{OR}=1.55,95 \% \mathrm{CI}: 0.80-3.01)$, and age $(B=-0.27, S E=0.31, p=.390, \mathrm{OR}=0.76,95 \% \mathrm{CI}: 0.40-1.42)$ did not show any significant effect on the probability of passing the first part of the teacher recruitment examination.

In Model 2B, neither perseverance of effort $(B=-0.12, S E=0.25, p=.626, \mathrm{OR}=0.88$, $95 \%$ CI: $0.54-1.44)$ nor consistency of interest $(B=-0.58, S E=0.32, p=.068, \mathrm{OR}=0.55,95 \%$ CI: 0.29-1.04) showed significant effects. In Model 2C, Grit-S, like the Grit Scale, did not show a significant effect $(B=-0.32, S E=0.40, p=.419, \mathrm{OR}=0.72,95 \% \mathrm{CI}$ : $0.32-1.59)$.

\subsection{Determinants of Probability of Passing the Second Part of the Teacher Re- cruitment Examination}

In Model 3A, scores for the Grit Scale showed a significant positive effect on whether students passed the second part of the teacher recruitment exam (failed $=0$, passed $=1 ; B=1.10, S E=$ $0.40, p=.006, \mathrm{OR}=3.00,95 \% \mathrm{CI}: 1.36-6.61$ ). In other words, consistent with the hypothesis, students with higher levels of grit were found to be more likely to pass the second part of the examination for teacher recruitment. Furthermore, gender $(B=0.62, S E=0.37, p=.042, \mathrm{OR}=$ 1.86, 95\% CI: $1.02-3.40)$ had a significant positive effect, and age $(B=-0.69, S E=0.33, p$ $=.036, \mathrm{OR}=0.49,95 \% \mathrm{CI}: 0.25-0.95)$ had a significant negative effect. On the other hand, self-control $(B=-0.40, S E=0.32, p=.201, \mathrm{OR}=0.66,95 \% \mathrm{CI}: 0.35-1.24)$ and GPA $(B=0.61$, $S E=0.37, p=.100, \mathrm{OR}=1.85,95 \% \mathrm{CI}: 0.88-3.88)$ did not show any significant effect on the probability of passing the second part of the teacher recruitment exam.

In Model 3B, perseverance of effort had a significant positive effect $(B=0.60, S E=0.24, p$ $=.014, \mathrm{OR}=1.82,95 \% \mathrm{CI}: 1.12-2.94)$. In other words, the students with higher perseverance of effort were more likely to pass the second part of the teacher recruitment examination. Consistency of interest, on the other hand, did not show a significant effect $(B=0.48, S E=0.27, p$ $=.079, \mathrm{OR}=1.62,95 \%$ CI: 0.94-2.81). In Model 3C, Grit-S and the Grit Scale showed a significant positive effect $(B=0.88, S E=0.37, p=.019, \mathrm{OR}=2.41,95 \% \mathrm{CI}: 1.15-5.04)$.

\section{Discussion}

This study examined the association between grit, a noncognitive skill, and results in a teacher recruitment examination. More specifically, we examined, through a longitudinal questionnaire survey of students at a Japanese teacher-training university, whether grit predicts the probabilities of taking the teacher recruitment exam and of passing the first and second parts of the exam. The results showed that students with higher levels of grit are both more likely to take the teacher recruitment exam and to pass the second part of the exam. Therefore, it can be said that the results are generally supportive of the hypothesis.

Grit and self-control were found to be positively correlated $(r=.59)$, which accords with the findings of previous studies [5]. While grit predicted the outcome of the teacher recruitment exam, self-control did not predict the outcome. Thus, grit has stronger predictive power than 
self-control regarding the achievement of long-term goals such as "becoming a teacher." These findings are consistent with previous research claims that grit and self-control are related but separable concepts [19].

Contrary to predictions made at the beginning of this study, although grit had a significant positive effect on the probabilities of taking the teacher recruitment examination and passing the second part of the examination, no significant effect on the probability of passing the first part of the examination was identified. A possible reason for this is that the first part of Japan's teacher recruitment examination, when compared to the second part, more closely resembles a simple measurement of cognitive ability (i.e., it comprises a mark-sheet type test that focuses on general education and specialized knowledge). In fact, the present study produced indirect evidence that supports this supposition, as cumulative GPA was found to have a positive effect on the likelihood of passing/failing the first part of the exam, but to have no significant effect in this regard for the second part. Grit, a type of noncognitive ability, is a distinct concept from cognitive ability. Thus, it is assumed that there is no association between grit and the probability of passing the first examination.

Based on the suggestions of a previous meta-analysis [6], this study also analyzed the impact of the two subfactors of the Grit Scale, perseverance of effort and consistency of interest, on the results of the teacher recruitment examination. The findings consequently showed that, while consistency of interest had a significant effect on the probability of taking the teacher recruitment exam, perseverance of effort had an effect on the probability of passing the second part of the exam. This result means that even if students have the perseverance to keep trying, they will not take the teacher recruitment exam unless they maintain their interest in the teaching profession, while they will not pass the second part of the exam unless they have the ability to work hard, even if they remain interested. Thus, the different aspects of grit affect different outcomes, which indicates the importance of analyzing the subfactors of the Grit Scale separately. Furthermore, the finding that only perseverance of effort was found to have a significant effect on pass rate is consistent with the findings of the meta-analysis, which showed that perseverance of effort has greater predictive power in relation to success and performance when compared with consistency of interest. Future application of grit in this field should take the differing natures of the subfactors into account.

The association between the Grits-S [7] and the teacher recruitment examination results showed a generally similar pattern to the corresponding association for the full-version of the Grit Scale [5]. On the other hand, the coefficient of determination (i.e., Nagelkerke $R^{2}$ ) was marginally higher for the model using the full-version of the Grit Scale than for the model using the Girt-S. This is consistent with research that indicates the conceptual inadequacies of Grit-S [8]. Therefore, it is preferable to use the full-version of the Grit Scale as long as there is room in the volume of the survey.

\subsection{Limitations}

Although the results of this study generally support the hypothesis, there are several limitations. First, we did not measure conscientiousness, one of the Big Five personality traits, which has a large conceptual overlap with grit. Conscientiousness refers to being competent, orderly, dutiful, achievement striving, self-disciplined, and deliberate [22]. While these aspects of conscientiousness and grit partially overlap, they are conceptually distinct in several ways. For example, grit is said to emphasize "long-term stamina" rather than "short-term intensity" in goal pursuit compared to conscientiousness [5], [7]. In other words, grit refers to the ability to maintain effort and interest in achieving long-term goals over several years. Moreover, people with high grit set 
relatively difficult goals and do not abandon their goal pursuit even in the absence of positive feedback. This feature of grit is distinct from the need for achievement facet of conscientiousness. Indeed, a meta-analysis also shows that perseverance of effort, a subfactor of grit, remains a significant effect on academic performance, even after controlling for the effects of conscientiousness [6]. Furthermore, the present study confirmed that grit continues to effect performance in the teacher recruitment exam even after controlling for the effects of self-control, which is strongly associated with conscientiousness. Nevertheless, future work is required to examine whether the results of this study can be replicated even after controlling for conscientiousness.

Second, we did not examine the influence mechanisms by which grit contributes to success in teacher recruitment exams. In a previous study, deliberate practice was found to be a factor that mediated the effects of grit [12]. Future research should examine whether students with high levels of grit (especially, perseverance of effort) spend more time in deliberate practice, performing the tasks required to become teachers (e.g., attending additional teaching-related classes and securing additional teaching practice) and, as a result, perform better in teacher recruitment exams.

Third, although this study was longitudinal, it was not experimental; it comprised only a survey. One significant feature of this study is that it was conducted in a longitudinal manner, unlike previous studies that involved cross-sectional analysis of the relationship between grit and teacher recruitment exam results [20]. However, to more precisely estimate causality, which will be required for the implementation of interventions, it is necessary to conduct an experimental study to manipulate the degree of grit.

\subsection{Implications}

What are the possible applications of the findings of this study in the context of IR in teacher-training universities? One aspect that should be considered is the implementation of educational interventions that increase the grit of current students as a means of improving the rate of teacher recruitment and the quality of teachers. This raises the question: what educational interventions can be used to improve grit? One leading method is a mindset-based intervention [23]. Mindset here refers to a belief in human abilities, and can be divided into "growth mindset" and "fixed mindset." Growth mindset refers to the belief that "human ability can be changed with effort," while fixed mindset refers to the belief that "human ability cannot be changed." Grit and growth mindset can be said to be conceptually related, in that they emphasize the effectiveness of effort. In fact, previous studies have repeatedly confirmed that grit and growth mindset are positively correlated [24].

The association between grit and mindset is confirmed from the earliest stages of development. For example, in an experiment with 13- to 18-month-old infants, observing successful adults who exerted effort confirmed that they persisted in tackling difficult tasks; this was not the case when observing successful adults who did not exert effort [25]. In observational studies, children of parents who praise effort for success have been shown to be more persistent than children of parents who praise their abilities [26].

Neuroscientific studies using resting-state functional magnetic resonance imaging (fMRI) have also shown that grit and mindset partially share a correlation with functional connectivity in the brain [27]. Furthermore, in recent years, it has been found that educational interventions that strengthen growth mindset can improve grit. In one study, an intervention experiment was conducted among elementary school children in Turkey for more than 10 weeks [28]. Children in the intervention group engaged in extracurricular activities (e.g., watching animated videos that highlighted that people can improve certain abilities) for approximately two hours each 
week, which were designed to reinforce their growth mindset. The results showed that the children who received the intervention showed higher levels of grit when responding to a self-report scale and engaged in behaviors that reflected higher grit, and they also showed a greater preference for difficult but highly rewarding tasks. While it is impractical to directly apply an intervention program for elementary school students to university students, it is worth noting that interventions that reinforce growth mindset increase grit.

In Japan, the mutual influence process between grit and growth mindset has been observed in a panel survey of university students [29]. Specifically, grit and growth mindset were measured in a questionnaire administered to teacher-training university students at three time points over a two-year period. Analyses using the cross-lagged panel model confirmed that grit and growth mindset had positive effects on each other. That is, students who had a stronger growth mindset at a given point in time were more likely to increase their subsequent grit, and vice versa. These results are meaningful in that they provide basic evidence for the implementation of an educational intervention to strengthen a growth mindset that increases grit in Japanese university students. For IR, it will be necessary in the future to develop effective intervention programs targeting undergraduates; these could be based on previous attempts conducted in the United States to develop grit-based interventions [30].

Another possible application of the present study findings is the utilization of grit in admissions selection. However, grit is primarily measured through a self-report scale (i.e., the Grit Scale) [5], and there are issues relating to this method that must be considered. In situations where positive self-presentation is required, such as in admissions, respondents may distort their answers to Grit Scale items in a socially desirable direction (i.e., level of grit may be graded higher than it actually is) [29]. Therefore, in order to eliminate the effects of social desirability when measuring grit during admissions, it is necessary to use more objective methods. One such method is the "Grit Grid," which is a scale that scores the experience and performance of completing extracurricular activities as a measure of grit [11]. More specifically, they are asked to freely describe the details, duration, and achievements of their extracurricular activities in a grid-like answer column. These responses are then scored by the coder in terms of the number of years of extracurricular activities and the level of performance, and are used as a grit indicator. The Grit Grid, like the Grit Scale, is a self-reported measure, but it is relatively easy to evaluate whether the answers are true or false by reviewing evidence such as activity history and awards, so it is unlikely to be affected by social desirability. Therefore, it is desirable to use the Grit Grid in measuring the level of grit one applied in taking the entrance examination. At present, several studies using the Grit Grid have been conducted in Japan [29]. This study confirms that Grit Grid scores are positively correlated with Grit Scale scores and that the higher the Grit Grid score, the better the academic performance. It will be necessary to examine whether grit at the time of admission affects the results of the teacher recruitment examination approximately four years later, before applying it in the admissions process.

It is also important to test the generalizability of the findings of this study. Specifically, it would be useful to examine the relationship between grit and results in exams other than the teacher recruitment exam (e.g., the National Medical Practitioners Qualifying Examination, bar examinations). If the exam requires long-term effort to pass and is relatively difficult, individual differences in grit are likely to predict the outcome of the exam. In other words, the higher the grit, the easier it would be to pass the exam. High grit is not only predictive of success in exams, but is also associated with a wide range of positive social consequences, such as job achievement after university and life satisfaction [9]. Therefore, it would be worthwhile to test the effectiveness of grit even in universities that do not train specific professionals. Future research should confirm the generalizability and robustness of the effects of grit by examining its role in a variety 
of domains.

The results of this study suggest that grit is a determinant of success in teacher recruitment examinations. This indicates that grit is an important factor in ensuring the number of teachers in Japan, where the competitive ratio of teacher recruitment examinations continues to decline. On the other hand, in teacher training, it is important to ensure not only the number but also the quality of teachers. Prior research confirms that grit can also have a positive effect on aspects of teacher quality. For example, teachers with higher grit have been shown to exhibit higher teaching ability and lower turnover rates [11]. Furthermore, grit has also been found to reduce burnout, to which human service professionals, including teachers, are particularly prone [31]. Burnout refers to the state of exhaustion of emotional energy and loss of motivation and interest in work [32]. Burnout consists of three aspects: emotional exhaustion (emotionally drained by work), depersonalization (impersonalization of service recipients), and reduced personal accomplishment (decreased sense of accomplishment related to human service duties). It is known that the more intense these symptoms of burnout are, the worse the job performance and the greater the intention to leave the job. Given the current situation in Japan, where the deterioration of teachers' mental health is considered a problem by the Ministry of Education, Culture, Sports, Science and Technology [33], it is important to note that improving grit can lead to the prevention of burnout in order to guarantee the quality of teachers produced by teacher-training universities. Therefore, it is necessary to conduct continuous follow-up surveys of graduates in the future to examine whether grit during their time in school has an impact on their teaching ability and social consequences such as burnout.

\subsection{Conclusions}

This study demonstrates the possibility that grit is an important concept that could help teacher-training universities address challenges regarding producing sufficient numbers of high-quality teachers. Specifically, using longitudinal data, we demonstrated that students with higher consistency of interest, a subfactor of grit, were more likely to take the teacher recruitment exam, and that students with higher perseverance of effort were more likely to pass the second part of the exam. The paper presents basic evidence that suggests that the implementation of grit-based education reforms can increase the rate of teacher recruitment and the quality of teachers. In the future, it will be necessary to confirm the robustness of the effects of grit and to provide more practical knowledge that can assist its application in IR.

\section{References}

[1] Author, "article title," in Proceedings of the 9th International Conference on Data Science and Institutional Research, page numbers, Sep. 2020.

[2] MEXT, "Points on the implementation status of the recruitment selection examination for public school teachers in the first year of Reiwa," Dec. 2019. [Online]. Available: https://www.mext.go.jp/content/20191223-mxt_000003296_111.pdf. Accessed: Nov. 24, 2020. (in Japanese)

[3] Hokkaido Prefectural Board of Education, "Hokkaido and Sapporo city public school teacher recruitment candidate registration status in the second year of Reiwa," Oct. 201 9. [Online]. Available: http://www.dokyoi.pref.hokkaido.lg.jp/hk/ksk/kishahappyou/R1. 10/R011015-1600.pdf. Accessed: Nov. 24, 2020. (in Japanese) 
[4] MEXT, "Results of redefining the mission of the teacher training field: Hokkaido university of education," Dec. 2013. [Online]. Available: https://www.mext.go.jp/compone nt/a_menu/education/detail/_icsFiles/afieldfile/2013/12/18/1342090_1.pdf. Accessed: Nov. 24, 2020. (in Japanese)

[5] L. Duckworth, C. Peterson, M. D. Matthews, and D. R. Kelly, "Grit: Perseverance and passion for long-term goals," J. Pers. Soc. Psychol., vol. 92, no. 6, pp. 1087-1101, Jun. 2007.

[6] M. Credé, M. C. Tynan, and P. D. Harms, "Much ado about grit: A meta-analytic synthesis of the grit literature," J. Pers. Soc. Psychol., vol. 113, no. 3, pp. 492-511, Sep. 2017.

[7] L. Duckworth and P. D. Quinn, "Development and validation of the short grit scale (grit-s)," J. Pers. Assess., vol. 91, no. 2, pp. 166-174, Mar. 2009.

[8] M. Credé, "What shall we do about grit? A critical review of what we know and what we don't know," Educ. Res., vol. 47, no. 9, pp. 606-611, Sep. 2018.

[9] L. Eskreis-Winkler, J. J. Gross, and A. L. Duckworth "Grit: Sustained self-regulation in the service of superordinate goals," in Handbook of self-regulation: Research, theory, and applications, K. D. Vohs and R. F. Baumeister, Eds. New York, NY, USA: Guilford, 2016, pp. 380-395.

[10] D. Duckworth et al., "Cognitive and noncognitive predictors of success," Proc. Natl. Acad. Sci. USA, vol. 116, no. 47, pp. 23499-23504, Nov. 2019.

[11] Robertson-Kraft and A. L. Duckworth, "True grit: Trait-level perseverance and passion for long-term goals predicts effectiveness and retention among novice teachers," Teach. Coll. Rec., vol. 116, no. 3, 030302, Nov. 2014.

[12] L. Duckworth, T. A. Kirby, E. Tsukayama, H. Berstein, and K. A. Ericsson, "Deliberate practice spells success: Why grittier competitors triumph at the national spelling bee" Soc. Psychol. Pers. Sci., vol. 2, non. 2, pp. 174-181, Mar. 2011.

[13] S. Carver and M. F. Scheier, "Self-regulation of action and affect," in Handbook of self-regulation: Research, theory, and applications, K. D. Vohs and R. F. Baumeister, Eds. New York, NY, USA: Guilford, 2016, pp. 3-23.

[14] J. P. Tangney, R. F. Baumeister, and A. L. Boone, "High self-control predicts good adjustment, less pathology, better grades, and interpersonal success." J. Pers., vol. 72, no. 2, pp. 271-324, Apr. 2004.

[15] T. de Ridder, G. Lensvelt-Mulders, C. Finkenauer, F. M. Stok, and R. F. Baumeister, Eds. "Taking stock of self-control: A meta-analysis of how trait self-control relates to a wide range of behaviors," Pers. Soc. Psychol. Rev., vo. 16, no. 1, pp. 76-99, Feb. 2012.

[16] Y. Shoda, W. Mischel, and P. K. Peake, "Predicting adolescent cognitive and self-regulatory competencies from preschool delay of gratification: Identifying diagnostic conditions," Develop. Psychol., vol. 26, no. 6, pp. 978-986, Nov. 1990. 
[17] E. J. Finkel and W. K. Campbell, "Self-control and accommodation in close relationships: an interdependence analysis," J. Pers. Soc. Psychol., vol. 81, no. 2, pp. 263-277. Aug. 2001.

[18] W. Hofmann, M. Luhmann, R. R. Fisher, K. D. Vohs, and R. F. Baumeister, "Yes, but are they happy? Effects of trait self-control on affective well-being and life satisfaction," J. Pers., vol. 82, no. 4, pp. 265-277, Aug. 2014.

[19] L. Duckworth and J. J. Gross, "Self-control and grit: Related but separable determinants of success," Curr. Dir. Psychol. Sci., vol. 23, no. 5, pp. 319-325, Oct. 2014.

[20] H. Takehashi, O. Higuchi, Y. Ozaki, T. Watanabe, and J. Toyosawa, "Reliability and validity of the Japanese version of the Grit Scale," Jap. J. Psychol., vol. 89, no. 6, pp. 580-590, Feb. 2019. (in Japanese)

[21] Y. Ozaki, T. Goto, M. Kobayashi, and G. Kutsuzawa, "Reliability and validity of the Japanese translation of Brief Self-Control Scale (BSCS-J)," Jap. J. Psychol., vol. 87, no. 2, pp. 144-154, Jul. 2016. (in Japanese)

[22] P. T. Costa and R. R. McCrae, "Five ways five factors are basic," Pers. Individ. Diff., vol. 13, no. 6, pp. 653-665, Jun. 1992.

[23] S. Dweck, Mindset: The new psychology of success, New York, NY, USA: Random House. 2006.

[24] M. R. West et al., "Promise and paradox: Measuring students' non-cognitive skills and the impact of schooling," Educ. Eval. Pol. Anal., vol. 38, no. 1, pp. 148-170, Mar. 2016.

[25] J. A. Leonard, Y. Lee, and L. E. Schulz, "Infants make more attempts to achieve a goal when they see adults persist," Science, vol. 357, no. 6357, pp. 1290-1294, Sep. 2017.

[26] K. Lucca, R. Horton, and J. A. Sommerville, "Keep trying!: Parental language predicts infants' persistence," Cognition, vol. 193, 104025, Dec. 2019.

[27] C. A. Myers, C. Wang, J. M. Black, N. Bugescu, and F. Hoeft, "The matter of motivation: Striatal resting-state connectivity is dissociable between grit and growth mindset," Soc. Cogn. Affect. Neurosci. vol. 11, no.10, Oct. 2016.

[28] S. Alan, T. Boneva, and S. Ertac, "Ever failed, try again, succeed better: Results from a randomized educational intervention on grit," Quart. J. of Econ., vol. 134, no. 3, pp. 1121-1162, Aug. 2019.

[29] R. Sakurai and T. Watanabe, "Examining the application of grit to educational IR: From the perspective of admissions and educational reform," in Proceedings of the 8th Meeting on Japanese Institutional Research, pp. 104-109, Dec. 2019. (in Japanese)

[30] SRI International, "Promoting grit, tenacity, and perseverance: Critical factors for success in the 21st century," Nov. 2018. [Online]. Available: https:/www.sri.com/publication/promoting-grit-tenacity-and-perseverance-critical-factors-for-success-in-the-21 stcentury/. Accessed: May 19, 2020. 
[31] A. Salles, G. L. Cohen, and C. M. Mueller, "The relationship between grit and resident well-being,” Am. J. Surg., vol. 207, no. 2, pp. 251-254, Feb. 2014.

[32] C. Maslach and S. E. Jackson, "The measurement of experienced burnout," J. Organ. Behav., vol. 2, no. 2, pp. 99-113, Apr. 1981.

[33] MEXT, “About work-style reform in schools," Jan. 2019. [Online]. Available: https://www.mext.go.jp/a_menu/shotou/hatarakikata/index.htm. Accessed: Nov. 24, 2020. (in Japanese) 